Dead" style. On the evidence of its precedence in time and its similar but simpler character, it is suggested that the "Beaches of the Dead" type may be ancestral to the Maya style. Posthumous distortion has destroyed the evidential value of the skeletal material, beyond an indication of a general physical resemblance to the type of the Maya people.

\section{Mosquito Control and Local Authorities}

ReFerence has been made in these columns on a number of occasions to the valuable work on mosquitoes and their control carried on by Mr. J. F. Marshall at the British Mosquito Control Institute, Hayling Island, Hampshire. The Institute was built and equipped by Mr. Marshall in 1925, and has become an important advisory and educational centre, which has been maintained almost entirely by him. Before he began his work, Hayling Island was infested with the salt-marsh mosquito and other species, but by dealing systematically with the breeding-places these pests have almost disappeared from the island. Experience has shown, however, that inspection and other control measures cannot be allowed to lapse if they are to be of practical value. This is evidently realized by the Havant and Waterloo District Council, which, in a Bill being presented to Parliament, includes a clause giving powers to the Council to "subscribe or contribute such sums as they may think fit to the British Mosquito Control Institute so long as that Institute shall remain established at Hayling Island and the Council shall consider its work contributory to the freeing of the district from mosquitoes".

HrTHERTo, consent of the owners of property has had to be obtained to examine an area suspected to contain breeding places of mosquitoes or to deal with it suitably. The Bill mentioned above empowers the local council to take whatever action it may consider necessary for health's sake to inspect such areas or carry out measures of mosquito control. The clause relating to these powers reads as follows : "The Council may take all reasonable measures to make and keep the district free from mosquitos and with this object they may in particular (apart from any other measures)-(a) enter by their officers upon any premises which they have reasonable grounds for suspecting to be a breeding place for mosquitos and apply thereon any tests or examination for the purpose of discovering whether and to what extent mosquitos or their larvæ are there; (b) require the owner of any premises upon which there is stagnant water or marshy ground which is a haunt or breeding place for mosquitos or contains the larvæ of mosquitos to drain the site of such water or such marshy ground to the reasonable satisfaction of the Council and to apply thereto such other treatment (if any) as the Council may reasonably prescribe." The inclusion of this clause in the Bill shows that the Council not only realizes the existence of mosquito pests but also the practicability of dealing with them by measures which have been successfully adopted during the past eleven years or so by Mr. Marshall as director of the British Mosquito Control Institute.

\section{Exhibition of Electric Illumination}

THE Science Museum is holding a Special Exhibition of Electric Illumination, which will remain open until April 25, 1937. Push-button demonstrations illustrate the principles involved in illuminating engineering practice, such as various types of reflection and transmission of light, reflection factors, effects of contrast, etc. Two full-sized rooms are devoted to decorative lighting and standard lighting system definitions. The great advances made in tungsten filament lamps are illustrated by exhibits showing the control now exercised during manufacture. The electric discharge lamp is dealt with in detail. Apart from examples of discharge lamps and their application to street lighting, industrial lighting and floodlighting, there are exhibits illustrating the cyclical form of the discharge and stroboscopic applications. All types from low-pressure tubes to water-cooled quartz tubes operating at $8,000^{\circ} \mathrm{C}$. are shown. The phenomenon of luminescence, discovered by Crookes in 1879 and now applied to discharge lamps, is shown in considerable detail. By way of contrast, a concise historical exhibit illustrates the state of illumination technique through the ages. The exhibition has been arranged by Mr. W. T. O'Dea, of the Science Museum, with the assistance of the E.L.M.A. Lighting Service Bureau and an advisory committee under the chairmanship of Mr. C. Rodgers.

THE opening ceremony was performed on December 15 by Lord Rutherford, with Sir Henry Lyons, the chairman of the Science Museum Advisory Council and a past director of the Museum, in the chair. Lord Rutherford remarked that the subject is one which has interested him all his life. During the past ten years, there have been remarkable advances in illumination which, emanating as they have from pure science research undertaken in industrial laboratories, illustrate admirably the close relationship between science and industry. 80 candle-hours ten years ago cost the same as 300 candle-hours to-day, and this improvement happily comes at a time when it is really wanted in the cause of road safety. Some 25,000 hot cathode discharge lamps now illuminate 1,000 miles of road in Great Britain alone. With regard to modern developments in the application of the phenomenon of luminescence, Lord Rutherford said he hopes to live to see the time when we shall obtain light without filaments or electrodes simply by the conversion of invisible radiation. Mr. H. T. Young, president of the Institution of Electrical Engineers, in proposing a vote of thanks, mentioned the valuable educational work which can be done by such an exhibition; it is expected that the exhibition will attract a quarter of a million visitors.

\section{Modern Views on Infection and Disinfection}

THIs was the subject of a Chadwick lecture delivered by Sir Weldon Dalrymple Champneys at Manson House, London, on December 9. Microbial diseases, he said, can be defined as a disturbance of health in man or other living things due to 
the presence of parasitic organisms, as a disturbance of the equilibrium between host and parasite unfavourable to the host. The reactions of any host to the presence of pathogenic organisms are numerous and complex, but are not mutually exclusive. Thus, the parasite may be rapidly killed by defensive meohanisms of the host's body, without giving rise to any symptoms of disease, or it may cause a local reaction known as inflammation. Fever is also a common result of infection, and tends to be a protective mechanism. Sir Weldon dwelt on the fact that a 'carrier state' may be established either following illness with apparent recovery without complete destruction of the invading parasite, or in consequence of a 'silent' infection without actual disease.

THE manner in which infecting parasites gain access to the body was then dealt with, the two commonest portals of entry being the skin and the nose and mouth. Infection may enter through the nose or mouth by the inhalation of infected droplets in the breath of patients or carriers, as with measles, influenza and others, or by swallowing infected food or drink, as in cholera and typhoid fever. The importance of the carrier state as a cause of cases or epidemics of infectious diseases was emphasized, and reference was made to the fact that different diseases may be caused by the same organism. For example, scarlet fever, tonsillitis, puerperal fever and probably acute rheumatism are all caused by various hæmolytic streptococci. In conclusion, Sir Weldon discussed measures of disinfection and prevention, and in regard to 'current' and 'terminal' disinfection, pointed out that treatment of infective material in the sick room during the patient's presence there ('current disinfection') is all that is necessary with most diseases. 'Terminal disinfection' after recovery or removal of the patient, upon which until recent years most reliance has been placed, is needless, and may be confined to the free use of soap and water with thorough ventilation.

\section{Discoveries in Antarctica}

A Dispatch from the British Graham Land Expedition under the leadership of Mr. J. Rymill published in The Times of December 12 announces an important change in the map of Graham Land. In December 1928 Sir Hubert Wilkins in his flight over Graham Land reported the existence of two straits, Casey Channel and Stefansson Strait, in about latitudes $69^{\circ} 45^{\prime} \mathrm{S}$. and $71^{\circ} \mathrm{S}$. respectively, across the area known as Graham Land which previously was thought to be united to the Antarctic Continent. Between the two straits he mapped roughly the Finley Archipelago. The British expedition, sledging along the west coast of Graham Land, to lat. $72^{\circ} \mathrm{S}$., long. $67^{\circ} \mathrm{W}$., or ninety miles south-west of where Sir H. Wilkins turned, found no trace of these two straits and believes that low glaciers must have been mistaken for ice-covered straits. Thus Graham Land south of Crane Channel in the Antaretic Circle is restored to its former continuity with the continent. A further discovery of importance is that Alexander I Land, discovered by Bellingshausen in 1821 and sighted by Charcot in 1909, is not a small island but a large land area at least two hundred and fifty miles from north to south and separated from Hearst Land by an ice-filled cleft-like strait fifteen miles wide and 200 miles long. The expedition charted the eastern coast line of this island. The strait appears to be a fault feature with the eruptive rocks of Graham Land on the east and fossiliferous sedimentary rocks on the west or island side.

\section{Hooker's Work on Lapachol and Related Compounds}

The yellow crystalline pigment lapachol, found in Bethabarra wood (from West Africa) as well as in several South American timbers, provided the late Dr. S. C. Hooker, the eminent American sugar technologist, with an absorbing problem in chemical structure which lasted a lifetime and has given us an admirable model of chemical research, based upon highly skilled technique, close observation, patience and careful deduction. The publication during the present year of no fewer than eleven posthumous papers by Dr. Hooker in the American Chemical Journal after a silence of forty years must have come as a complete surprise to organic chemists. But the work to which Dr. Hooker was so devotedly attached was interrupted by his long period of activity in industry. On his retirement in 1915 , he resumed the problems which had remained untouched since 1896, and he was reluctant to publish prematurely the numerous results which he was able to collect in the last twenty years of his life.

Hooker was born in Kent of British parents, but after studying in London under Japp and at Munich under Bamberger, with whom he undertook the investigation of retene, he migrated to the United States. His published work contains an account of the properties and structure of lapachol and of many closely allied compounds. Many of his results were obtained by close observation of minute samples under a microscope. Lapachol is a $\beta$-amylene $\beta$-hydroxy $\alpha$-naphthoquinone, which undergoes isomerism with mineral acids into lapachone, involving ring-closure with the hydroxy-group and sometimes also change to the orthoquinone structure. But further structural changes of an unusual type are readily induced and we cannot fail to admire the skill with which he solved the problems of change of structure from the $p$-quinone to the $o$-quinone type, of the exact location of the double bond in the amylene group and of the mechanism of the process of oxidation, whereby the quinone-ring is first broken with elimination of carbon dioxide and then re-formed from the side-chain, in such a way that the next lower homologue of the original compound is formed. A memorial volume containing an obituary notice from the Journal of the Chemical Society, together with reprints of twenty-two memoirs from the same journal and the Journal of the American Chemical Society, has been edited by Prof. L. F. Fieser of the Converse Memorial Laboratory, Harvard University, to whom application may be made for copies. 